\title{
On the analytical approach for modeling photovoltaic systems behavior
}

\author{
Javier Cubas $^{\mathbf{a}, *}$, Santiago Pindado ${ }^{a}$, Marta Victoria ${ }^{b}$
}

\begin{abstract}
A B S T R AC T
The 1-diode/2-resistors electric circuit equivalent to a photovoltaic system is analyzed. The equations at particular points of the $I-V$ curve are studied considering the maximum number of terms. The maximum power point as a boundary condition is given special attention. A new analytical method is developed based on a reduced amount of information, consisting in the normal manufacturer data. Results indicate that this new method is faster than numerical methods and has similar (or better) accuracy than other existing methods, numerical or analytical.
\end{abstract}

\section{Introduction}

The use of renewable energy is a big concern in modern societies, and among the different sources, photovoltaic energy is one of the most relevant in terms of increase of installed power. This fact, together with other more specific applications (e.g. satellites and spacecraft), has led scientists to study the behavior of photovoltaic cells and the methods to optimize their power generation. From the middle of the twentieth century, descriptions of the mechanisms that rule the conversion of solar radiation into electric power have been published [ $1-6]$. In addition, great efforts have been exerted to develop equivalent electrical/mathematical models to analyze the behavior of solar cells under different conditions, mainly different radiation levels and cell temperatures.
An electrical model consists in a simple circuit whose behavior fits the real behavior of a solar cell (see Figs. 1 and 2). The use of these circuit models, together with the correct definition of the electric parameters involved, is extremely important to maximize the power extracted from the cell working under real conditions. Also, the use of equivalent circuit models makes the simulation of more complex power systems that include solar cell panels possible. It should be pointed out that sometimes these power systems can have a very complicated behavior (e.g. in space applications these systems include batteries and programmed power consumptions, with important temperature gradients and different radjation levels affecting the output voltage of the solar panels, and must be optimized to ensure the survival of the satellite/ spacecraft).

The photoelectric effect is responsible for transforming the radiation on the solar cells into electric energy. In general, the easiest way to characterize a solar cell is by considering a current source connected in parallel to an ideal diode (see Fig. 2a) $[1,2,5]$. 

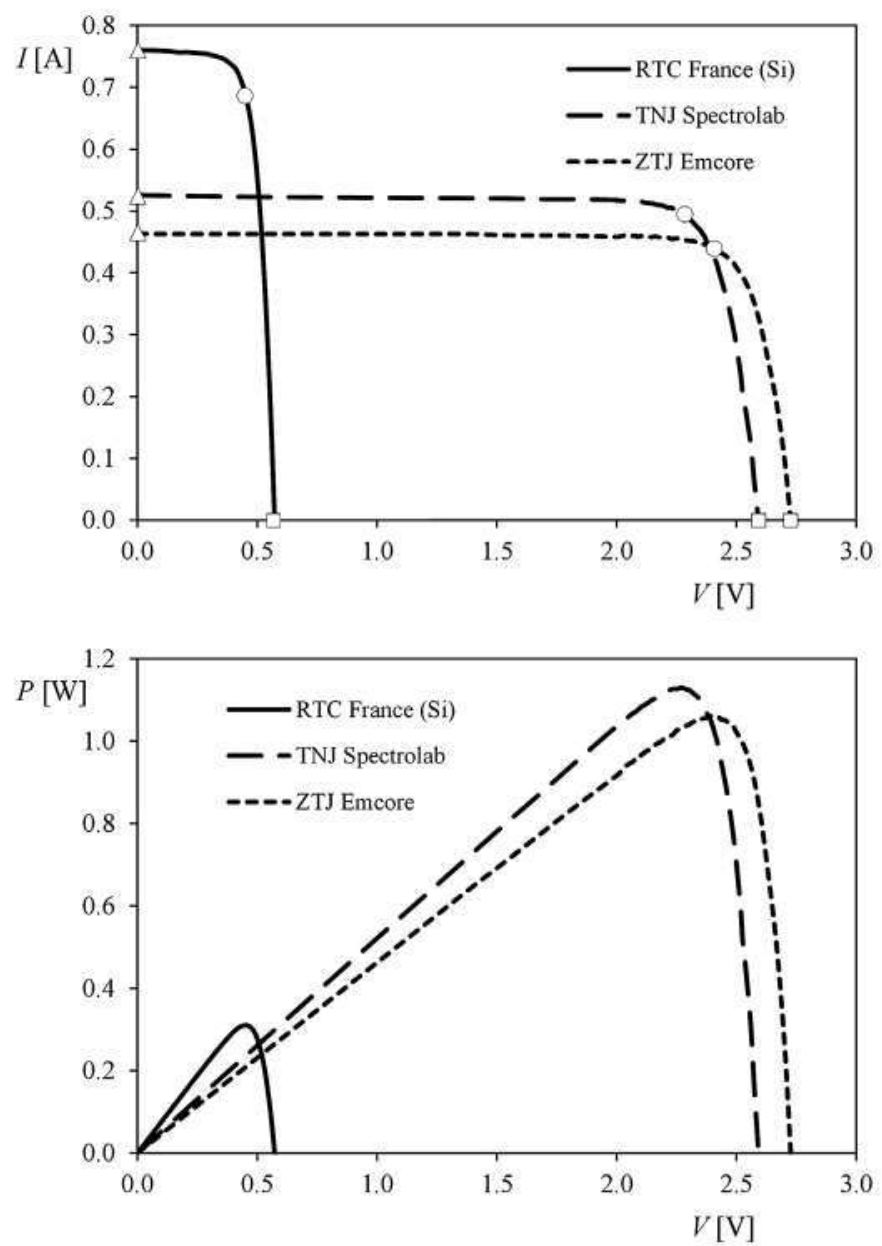

Fig. 1. Top: Current-voltage $(I-V)$ curves of different solar cells: silicon (Si) cell from R.T.C. (La Radiotechnique Compelec, Paris, France), measured with 8096 microcomputer (Commodore, West Chester, Pennsylvania) at $33^{\circ} \mathrm{C}$ [11]; TNJ triple-junction (GaInP2/GaAs/Ge) cell from Spectrolab (Sylmar, California, USA), measured at AM0 $1353 \mathrm{~W} \mathrm{~m}^{2}$ - and $28^{\circ} \mathrm{C}$; and ZT] triple-junction (InGaP/InGaAs/Ge) cell from Emcore (Albuquerque, New Mexico, USA), measured at AM0 $-1353 \mathrm{~W} \mathrm{~m} \mathrm{~m}^{2}$ and $28^{\circ} \mathrm{C}$. In every curve short circuit (triangles), maximum power (circles), and open circuit (squares) points are indicated. Bottom: Power curve of these solar cells. Data from TNJ and ZTJ solar cells extracted from the manufacturer datasheets.

The equation that describes the behavior of the solar cell is then composed of two terms, one related to the source and the other to the $\mathrm{p}-\mathrm{n}$ junction (which is, in fact, Shockley's ideal diode equation) [5]:
$I=I_{p v}-I_{0}\left[\exp \left(\frac{q V}{k T}\right)-1\right]$

The first term of the expression above, $I_{p v}$, is the photocurrent delivered by the constant current source, the second term is the ideal recombination current from the diffusion and recombination of electrons and holes in $\mathrm{p}$ and $\mathrm{n}$ sides of the cell (Shockley diffusion theory), where $I_{0}$ is the reverse saturation current corresponding to it, $T$ is the temperature and $k$ is the Boltzmann constant. Finally, $q$ is the charge of the electron. The last three constants are usually grouped into the so called thermal voltage, $V_{T}$ :

$V_{T}=\frac{k T}{q}$.

To improve expression (1) and to better fit cell behavior, two resistors are usually added to the circuit (see Fig. 2c). One resistor (the shunt resistor, $R_{s h}$ ), represents the current leakage through the high conductivity shunts across the $\mathrm{p}-\mathrm{n}$ junction and is added in parallel with the source and the diode. The other (the series resistance, $R_{s}$ ), is connected in series and represents the losses in cell solder bonds, interconnection, junction box, etc. [4,7]. Also, a non-dimensional constant, $a$, is added to the term of the recombination current in the $\mathrm{p}$ - and $\mathrm{n}$-sides. This constant is called the ideality or quality factor (or sometimes emission coefficient), and it takes into account the deviation of the diodes from the Shockley diffusion theory (the value of this factor, $a$, is assumed to be constant and between 1 and 1.5 for one-junction cells $[8,9]$, although some authors suggest that it depends on the ratio between the current, $I$, and voltage, $V$, of the cell [10]). The 1-diode/2-resistors circuit model is then defined by the expression:

$I=I_{p v}-I_{0}\left[\exp \left(\frac{V+I R_{S}}{a V_{T}}\right)-1\right]-\frac{V+I R_{S}}{R_{s h}}$.

Another change to the solar cell model was proposed in 1961 by Wolf and Rauschenbach [4]. These authors suggested that the $I-V$ characteristics of silicon solar cell are more accurately represented by a double exponential expression (see Fig. 2d), the second exponential standing for the current from the recombination of electrons and holes in the depletion region, which dominates at lower forward-bias voltages. The behavior of the solar cell can be then translated into the following equation:

$$
\begin{aligned}
I= & I_{p v}-I_{01}\left[\exp \left(\frac{V+I R_{S}}{a_{1} V_{T}}\right)-1\right]-I_{02}\left[\exp \left(\frac{V+I R_{S}}{a_{2} V_{T}}\right)-1\right] \\
& -\frac{V+I R_{S}}{R_{S h}}
\end{aligned}
$$

a)

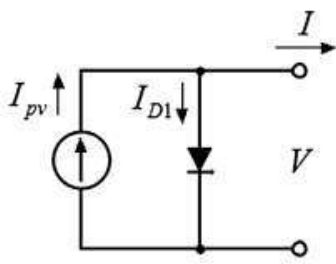

b)

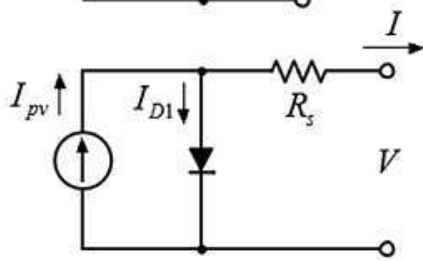

c)

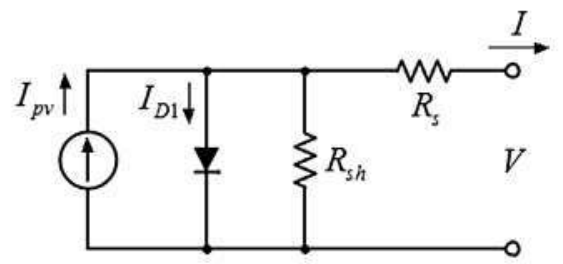

d)

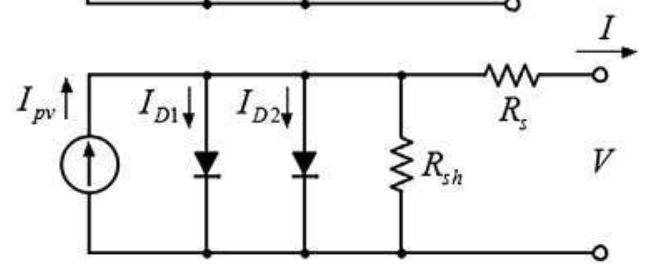

Fig. 2. Different circuit models to study the behavior of solar cells. (a) 1-diode; (b) 1-diode/1-resistor; (c) 1-diode/2-resistors; (d) 2-diodes/2-resistors. 
where $I_{01}$ and $I_{02}$ are the saturation currents of each diode, and $a_{1}$ and $a_{2}$ the ideality factors that take into account the deviation of the diodes from the Shockley diffusion theory, $a_{1}$ is close to 1 while $a_{2}$ is frequently greater than 2 .

The above 2-diode/2-resistors electrical model has been used by some authors to study solar cell performance [7,12-15]. However, it is quite complicated, since up to seven constants (only six if, as said, the hypothesis $a_{1} \sim 1$ is assumed, or five if $a_{2} \sim 2$ is also assumed) must be defined by experimental testing at defined levels of irradiance and temperature. On the other hand, it should be said that the simpler and more frequently used 1-diode/2-resistors model correctly represents the behavior of the solar cell around the maximum power point, that is, at high voltage levels $[16,17]$. This model simplifies the analysis of the solar cell behavior as a function of the different circuit variables [18-21], and has been used to analyze the effect of the irradiance and the temperature on the cell behavior $[22,23]$.

An even more simplified version of the solar cell circuit, the 1diode/1-resistor model (Fig. 2b), has been proposed by some authors to study a specific aspect of the solar cell, such as the series resistor or as its behavior under particular conditions [4,24]. Finally, it should be also mentioned that each model can be the best option depending on the solar cell characteristics $[14,25]$. The above theoretical approximations to solar cell behavior are widely accepted, nevertheless, some new models have arisen describing the solar cell as a multiple-zone element, with different electrical behavior within these zones $[26,27]$.

Once the circuit model has been chosen to study a particular solar cell (or solar cell array), it must be adjusted (that is, the value of the circuit parameters must be estimated as accurately as possible). These calculations can be based on the calibration results of the cell, that is, once the $I-V$ curve has been measured under certain irradiance and temperature conditions in a laboratory, the parameters of the model can be adjusted to give the best possible fit to this curve [11,28-33]. However, sometimes the only information available to adjust the selected circuit model comes from the manufacturer, and it is limited to only certain points of the $I-V$ curve (short circuit, open circuit, and maximum power points, see Fig. 1) $[8,18,34-38]$. Finally, with regard to the methods developed to adjust the parameters of the selected circuit model, some of them are numerical $[14,15,19,20,39,40]$ whereas some others are analytical $[2,41-43]$.

Analytical methods have the advantage of being simple and fast. However, such methods are normally based on experimental characteristics of the $I-V$ curve, that is, they require extensive testing results [44]. On the other hand, some authors have developed numerical methods to adjust the electric circuit parameters to the mentioned characteristic point of the curve $[8,9,38]$. This approach is quite interesting, as it uses only a few data to allow final users to analyze the performance of photovoltaic systems.

In the present work an analytical method for photovoltaic equivalent electric circuit parameters extraction is presented. This methodology is based only on manufacturers' data. As far as the authors know, and according to a recent review [44], this approach to the parameter extraction problem does not seem to have been studied as yet. The analytical procedure is explained in Section 2 of the present work, whereas some application examples are included in Section 3, together with a comparison with the results from other numerical and analytical methods.

\section{Solar cell modeling, the 1-diode/2-resistors model}

A brief discussion on this model is included here as the basis to explain the work performed in the present paper. As stated above, the 1-diode/2-resistors circuit model is one of the most commonly used to study the behavior of solar cells and photovoltaic systems. The equation that describes the solar performance (that is, the relationship between electric current, $I$, and voltage $V$ ) of this model is Equation (3) [20], reproduced here for convenience:

$I=I_{p v}-I_{0}\left[\exp \left(\frac{V+I R_{s}}{a V_{T}}\right)-1\right]-\frac{V+I R_{s}}{R_{s h}}$,

where $I_{p v}$ is the photovoltaic current, $I_{0}$ is the saturation current of the diode, $R_{S}$ is the series resistance, $R_{s h}$ is the shunt resistance, and $a$ the ideality factor of the diode. Finally, the thermal voltage of the cell, $V_{T}$, is a known quantity defined by Equation (2).

Obviously, prior to the use of this model to simulate the cell behavior it is necessary to identify the five parameters, $I_{p w}, I_{0}, R_{s}, R_{s h}$ and $a$. To calculate them, five boundary conditions extracted from the solar cell $I-V$ curve are needed. These boundary conditions can be obtained either from the manufacturer's data, or by testing the solar cell. As an example of the data normally available, the values of the most representative points (short circuit: $V=0, I=I_{s c}$; open circuit: $V=V_{o c}, I=0$; and maximum power: $V=V_{m p}, I=I_{m p}$ points) of the measured $I-V$ curve from different solar cells are included in Table 1 , together with the temperature during the test. These data must be translated into boundary conditions to obtain the five parameters of the model. The values of the 1-diode/2-resistors circuit model parameters related to the cells from Table 1 are included in Table 2. These parameters were obtained by the authors both numerically or analytically depending on each case.

As mentioned, most solar cells manufacturers include in the specifications datasheet, at the least, information with regard to the most representative points of the $I-V$ curve, that is, short circuit, open circuit, and the maximum power point. With these three points (indicated in Fig. 1 for three different solar cells), it is possible to derive four boundary conditions for Equation (5). Then, if no other information with regard to the $I-V$ curve is available either from the manufacturer or from a testing regime, it is possible to obtain a solution that represents an approximation to the solar cell performance, as a function of the ideality factor, $a$. For single junction solar cells, it is suggested to give an initial value of this factor in the bracket $[1,1.5]$, in order to reduce the number of parameters to four $[8,9,38]$. As the curvature of the $I-V$ curve is

\section{Table 1}

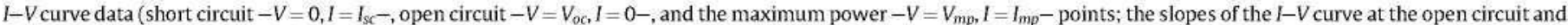

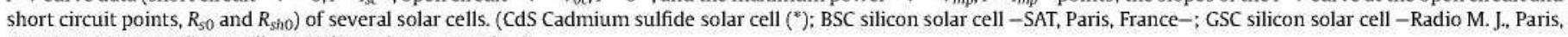
France-; Q6LM ${ }^{\mathrm{rm}}$ silicon cell $-\mathrm{Q}-$ Solar, Calgary, Canada-).

\begin{tabular}{|c|c|c|c|c|c|c|c|c|}
\hline Reference & Cell & $V_{o c}\{\mathrm{~V}\}$ & $I_{S c}\{\mathrm{~A}\}$ & $V_{m p}\{\mathrm{~V}\}$ & $I_{m p}\{\mathrm{~A}\}$ & $R_{\text {sho }}\{\Omega\}$ & $R_{50}\{\Omega\}$ & $T\{\mathrm{~K}\}$ \\
\hline Kennerud, 1969 [20] & CdS & 0.420 & 0.804 & 0.316 & 0.698 & 20 & 0.08 & \\
\hline Charles, 1981 [21] & BSC & 0.536 & 0.1023 & 0.437 & 0.0925 & $1000 \pm 30$ & $0.45 \pm 0.01$ & 300 \\
\hline Charles, 1981 [21] & GSC & 0.524 & 0.561 & 0.390 & 0.481 & $25.9 \pm 0.8$ & $0.162 \pm 0.005$ & 307 \\
\hline Lo Brano, 2010 [43] & Q6LM & 0.608 & 7.665 & 0.513 & 7.174 & 9.967 & 0.00443 & 298 \\
\hline
\end{tabular}

$\left({ }^{*}\right)$ No information concerning the manufacturer of this cell was included in Ref. [20]. 
Table 2

1-Diode/2-resistors circuit model parameter values from different solar cells.

\begin{tabular}{|c|c|c|c|c|c|c|}
\hline Reference & Cell & $R_{S}\{\Omega\}$ & $R_{\text {sh }}\{\Omega\}$ & $I_{p v}\{\mathrm{~A}\}$ & $I_{0}\{\mathrm{~A}\}$ & $a$ \\
\hline Kennerud, 1969 [20] & cdS & 0.03 & 20.3 & 0.805 & $1.84 \cdot 10^{-5}$ & 1.37 \\
\hline Charles, 1981 [21] & BSC & $0.070 \pm 0.009$ & $1000 \pm 50$ & $0.1023 \pm 0.0005$ & $(1.10 \pm 0.05) \cdot 10^{-7}$ & $1.51 \pm 0.07$ \\
\hline Charles, 1981 [21] & GSC & $0.08 \pm 0.01$ & $26 \pm 1$ & $0.5625 \pm 0.0005$ & $(6 \pm 3) \cdot 10^{-6}$ & $1.72 \pm 0.08$ \\
\hline Lo Brano, 2010 [43] & Q6LM & $7.7315 \cdot 10^{-5}$ & 9.9672 & 7.65549 & $7.87236 \cdot 10^{-8}$ & 1.28670 \\
\hline
\end{tabular}

affected by this parameter, its value may be adjusted once the other parameter values have been calculated [40].

The short-circuit conditions once introduced in Equation (5), lead to the following expression [20]:

$I_{s c}=I_{p v}-I_{0}\left[\exp \left(\frac{I_{s c} R_{s}}{a V_{T}}\right)-1\right]-\frac{I_{s c} R_{S}}{R_{s h}}$.

In Table 3 the values of each term of this expression are included. These values, obtained from different references (see Tables 1 and 2), can be used to evaluate the relative importance of each term. As a result, the second term of the right side of (6) can be neglected $[20,45]$, and the expression above can be rewritten as:

$I_{p v}=\frac{R_{s h}+R_{s}}{R_{s h}} I_{s c}$

From the open circuit conditions, Equation (5) can be rewritten as [20].

$0=I_{p v}-I_{0}\left[\exp \left(\frac{V_{o c}}{a V_{T}}\right)-1\right]-\frac{V_{o c}}{R_{s h}}$

Again, it is possible to estimate the magnitude of each term of the above equation (see Table 4). Some authors leave aside the last term of expression $(8)[8,37]$, whereas others keep it $[20,42,45]$. Taking into account that the value of this term is higher than the lowest one remaining in expression (6), it has been conserved in the present calculations. Finally, from Equations (7) and (8), the saturation current, $I_{0}$, can be reduced to:

$I_{0}=\frac{\left(R_{s h}+R_{s}\right) I_{S C}-V_{o c}}{R_{s h} \exp \left(\frac{V_{o c}}{a V_{T}}\right)}$

If Equation (5) is evaluated at the maximum power point, the following expression is obtained:

$I_{m p}=I_{p v}-I_{0}\left[\exp \left(\frac{V_{m p}+I_{m p} R_{s}}{a V_{T}}\right)-1\right]-\frac{V_{m p}+I_{m p} R_{S}}{R_{s h}}$.

Once more, analyzing relative magnitude of the different terms of the expression above, it is possible to neglect the second term inside the brackets. Finally, the following expression without dependence of $I_{p v}$ and $I_{0}$ can be derived from Eqs. (7), (9) and (10) [45]:

$$
\begin{aligned}
I_{S c}- & \left(I_{s c}-\frac{V_{o c}-R_{S} I_{s c}}{R_{s h}}\right)\left[\exp \left(\frac{V_{m p}+I_{m p} R_{S}-V_{o c}}{a V_{T}}\right)\right] \\
- & \frac{V_{m p}+I_{m p} R_{S}-I_{S c} R_{S}}{R_{S h}}=I_{m p} .
\end{aligned}
$$

The fourth condition to be analyzed to obtain the four parameters is the power peak at the maximum power point. This condition has been obviated by some authors in analytical formulations $[41,42]$. However, for a better simulation around the maximum power point it is quite important to force the solution to satisfy it. As it is well known, the electric power can be expressed as:
$P=I V$

which, differentiated once with respect to $V$, results in Ref. [20]:

$\frac{\partial P}{\partial V}=V \frac{\partial I}{\partial V}+I=0$.

Imposing the peak power condition $(P=0)$ to the equation above, the following expression is obtained $[20,46]$ :

$\left.\left(\frac{\partial I}{\partial V}\right)\right|_{\left[I_{m p}, V_{m p}\right]}=-\frac{I_{m p}}{V_{m p}}$.

Taking also into account Equation (5) differentiated once with respect to $V$, it is possible to obtain the following expression from Equation. (14):

$\frac{\mathrm{d} I}{\mathrm{~d} V}=-\frac{I_{0}}{a V_{T}}\left(1+\frac{\mathrm{d} I}{\mathrm{~d} V} R_{\mathrm{s}}\right)\left[\exp \left(\frac{V+I R_{\mathrm{s}}}{a V_{T}}\right)\right]-\frac{1}{R_{\mathrm{sh}}}\left(1+\frac{\mathrm{d} I}{\mathrm{~d} V} R_{\mathrm{s}}\right)$.

On the other hand, taking into account expressions (7), (9) and (11), it is possible to derive from Equation. (15) an implicit expression of the series resistor, $R_{5}$, as a function of the initial parameters:

$$
\begin{aligned}
& \frac{a V_{T} V_{m p}\left(2 I_{m p}-I_{s c}\right)}{\left(V_{m p} I_{s c}+V_{o c}\left(I_{m p}-I_{s c}\right)\right)\left(V_{m p}-I_{m p} R_{S}\right)-a V_{T}\left(V_{m p} I_{s c}-V_{o c} I_{m p}\right)} \\
& =\exp \left(\frac{V_{m p}+I_{m p} R_{s}-V_{o c}}{a V_{T}}\right) .
\end{aligned}
$$

And finally, the above expression combined with Equation (11) leads to the final expression of the shunt resistor, $R_{s h}$, as a function of $R_{S}$ and the initial parameters:

$R_{s h}=\frac{\left(V_{m p}-I_{m p} R_{S}\right)\left(V_{m p}-R_{S}\left(I_{s c}-I_{m p}\right)-a V_{T}\right)}{\left(V_{m p}-I_{m p} R_{S}\right)\left(I_{s c}-I_{m p}\right)-a V_{T} I_{m p}}$

As stated above, the use of the above equations is based on a previous estimation of the ideality factor, $a$. An alternative to this procedure consists in using other specific characteristics of the $I-V$ curve, such its slopes at the short circuit and open circuit points, $R_{s h 0}$ and $R_{s 0}$ respectively:

Table 3

Values of every term from Equation (6), obtained for different solar cells (calculated with coefficients from Tables 1 and 2).

\begin{tabular}{llllll}
\hline Reference & Cell & $I_{S C}$ & $I_{p v}$ & $I_{0}\left[\exp \left(\frac{I_{s} R_{s}}{a V_{S}}\right)-1\right]$ & $\frac{I_{s} R_{s}}{K_{s h}}$ \\
\hline Kennerud, 1969[20] & CdS & 0.8040 & 0.8050 & $1.56 \cdot 10^{-5}$ & $1.19 \cdot 10^{-3}$ \\
Charles, 1981[21] & BSC & 0.1023 & 0.1023 & $2.21 \cdot 10^{-8}$ & $7.16 \cdot 10^{-6}$ \\
Charles, 1981[21] & GSC & 0.5610 & 0.5625 & $1.01 \cdot 10^{-5}$ & $1.73 \cdot 10^{-3}$ \\
Lo Brano, 2010[43] & Q6LM & 7.6650 & 7.6555 & $1.42 \cdot 10^{-9}$ & $5.95 \cdot 10^{-5}$ \\
\hline
\end{tabular}


Table 4

Values of every term from Equation (8), obtained for different solar cells (calculated with coefficients from Tables 1 and 2).

\begin{tabular}{llllll}
\hline Reference & Cell & $I_{p v}$ & $I_{0}\left[\exp \left(\frac{V_{v}}{a V_{p}}\right)\right]$ & $I_{0}$ & $V_{\text {oc }}$ \\
\hline Kennerud, 1969 & CdS & 0.8050 & 0.7996 & $1.84 \cdot 10^{-5}$ & $2.07 \cdot 10^{-2}$ \\
Charles, 1981 & BSC & 0.1023 & 0.1006 & $1.10 \cdot 10^{-7}$ & $5.36 \cdot 10^{-4}$ \\
Charles, 1981 & GSC & 0.5625 & 0.5992 & $6.00 \cdot 10^{-6}$ & $2.02 \cdot 10^{-2}$ \\
Lo Brano, 2010 & Q6LM & 7.6555 & 7.6660 & $7.87 \cdot 10^{-8}$ & $6.10 \cdot 10^{-2}$ \\
\hline
\end{tabular}

$R_{\text {sho }}=-\left.\left(\frac{\partial V}{\partial I}\right)\right|_{I=I_{s c}}$,

$R_{S 0}=-\left.\left(\frac{\partial V}{\partial I}\right)\right|_{V=V_{o c}}$,

These slopes of the $I-V$ curve have frequently been used in calculations to fit the electric model behavior to the experimental results $[20,21]$. With regard to the practical use of these parameters, empirical methods to estimate them have been recently developed for photovoltaic arrays [47].

To calculate the ideality factor, $a$, it seems better to use the slope at the short circuit point, $R_{s h o}$, instead of the slope at the open circuit point, $R_{50}$, as the additional boundary condition. In this way, the final expressions of the method have a more simple form. It should also be mentioned that some authors prefer to use this boundary condition in their calculations to fit their models to the $I-$ $V$ curve $[18,45]$, instead of the slope of the curve at the open circuit point (expression (19)).

Once the value of $R_{\text {sho }}$ has been estimated, the additional boundary condition at the short circuit point can be expressed as [42]:

$\frac{1}{R_{s h}}-\frac{1}{R_{s h 0}-R_{S}}+\frac{I_{0}}{a V_{T}} \exp \left(\frac{R_{S} I_{S c}}{a V_{T}}\right)=0$.

Taking into account a magnitude analysis of the terms included in the above equation (see Table 5), it can be simplified as:

$\frac{1}{R_{\text {sh }}}-\frac{1}{R_{\text {sh } 0}-R_{S}}=0$

which leads to the following expression:

$R_{\text {sho }}=R_{\text {sh }}+R_{\mathrm{s}}$.

Some authors $[18,41,42,45]$, have simplified the above equation as:

$R_{\text {sho }}=R_{\text {sh }}$.

Nevertheless, in the present work the whole expression (22) has been kept, because in the case of solar panels the ratio $R_{s} / R_{s h}$ seems to grow directly as a function of the number of cells connected in series, so there may be cases were $R_{S}$ should not be neglected.

Table 5

Values of every term from Equation (20), obtained for different solar cells (calculated with coefficients from Tables 1 and 2).

\begin{tabular}{lllll}
\hline Reference & Cell & $\frac{1}{R_{\mathrm{jh}}}$ & $\frac{1}{R_{\mathrm{sto}} R_{3}}$ & $\frac{I_{0}}{a V_{\mathrm{T}}} \exp \left(\frac{I_{\mathrm{S}} R_{\mathrm{S}}}{a V_{\mathrm{S}}}\right)$ \\
\hline Kennerud, 1969 & CdS & 0.049 & 0.050 & $8.64 \cdot 10^{-4}$ \\
Charles, 1981 & BSC & 0.001 & 0.001 & $3.38 \cdot 10^{-6}$ \\
Charles, 1981 & GSC & 0.038 & 0.039 & $3.53 \cdot 10^{-4}$ \\
Lo Brano, 2010 & Q6LM & 0.100 & 0.100 & $2.42 \cdot 10^{-6}$ \\
\hline
\end{tabular}

Table 6

Manufacturer's data from a KC200GT solar array [8,9]. The corresponding values from the equivalent electric circuit calculated with the proposed method have also been included.

\begin{tabular}{lcc}
\hline & Manufacturer's data & Present method \\
\hline$I_{m p}\{\mathrm{~A}\}$ & 7.61 & 7.6100 \\
$V_{m p}(\mathrm{~V}\}$ & 26.3 & 26.3000 \\
$P_{m p}(\mathrm{~W}\}$ & 200.143 & 200.1430 \\
$I_{s c}\{\mathrm{~A}\}$ & 8.21 & 8.2100 \\
$V_{o c}\{\mathrm{~V}\}$ & 32.9 & 32.9000 \\
$N$ & 54 & 54 \\
\hline
\end{tabular}

With Equations (22) and (17) it is possible to derive an expression that gives the ideality factor as a function of constants already known, $R_{s}$ and the slope $R_{\text {sh } 0}$ :

$a V_{T}=\frac{\left(V_{m p}-I_{m p} R_{s}\right)\left(V_{m p}+\left(I_{m p}-I_{s c}\right) R_{s h 0}\right)}{\left(V_{m p}-I_{m p} R_{s h 0}\right)}$.

Finally, introducing Equation (24) in expression (16) and reorganizing the remaining terms, the value of the series resistor, $R_{5}$, is obtained:

$R_{5}=\frac{(A-B)}{(A+B)} \frac{V_{m p}}{I_{m p}}+\frac{B}{(A+B)} \frac{V_{o c}}{I_{m p}}$,

where:

$A=\left(V_{m p}+\left(I_{m p}-I_{s c}\right) R_{s h 0}\right) \log \left(\frac{V_{m p}+\left(I_{m p}-I_{s c}\right) R_{s h 0}}{V_{o c}-I_{s c} R_{s h 0}}\right)$

and,

$B=V_{m p}-R_{s h 0} I_{m p}$

\section{Results and discussion}

In Table 6 the manufacturer's data of a KC200GT solar array (Kyocera, Scottsdale, Arizona), is included [8,9]. These parameters were measured at $25^{\circ} \mathrm{C}$ and A.M1.5 $\left(1000 \mathrm{~W} \mathrm{~m}^{-2}\right)$. In Table 7 the results obtained with the present method are included, together with the ones from the numerical method proposed by Villalva et al. (2009). The procedure followed for the present calculations can be summarized as:

- Estimate the parameter $a$. In this case, the value of the ideality factor was chosen to be the same selected by Villalva et al. (2009). See Table 7.

- Obtain $R_{s}$ from expression (16).

- Obtain $R_{s h}$ from expression (17).

- Obtain $I_{0}$ from expression (9).

- Obtain $I_{p v}$ from expression (7).

It can be observed in Table 7 that the results are very similar to the ones obtained by the other authors. Also, in Table 6 the values of

Table 7

Parameters of 1-diode/2-resistors circuit model adjusted with the presented methodology to the KC200GT solar array. The results from Refs. $[8,9]$, have also been included in the table.

\begin{tabular}{llllll}
\hline Model & $a$ & $R_{s}\{\Omega\}$ & $R_{5 i}\{\Omega\}$ & $I_{0}\{\mathrm{~A}\}$ & $I_{p v}\{\mathrm{~A}\}$ \\
\hline $\begin{array}{l}\text { Present } \\
\quad \text { method -analytical- }\end{array}$ & 1.3 & 0.2308 & 597,3855 & $9.7631 \cdot 10^{-8}$ & 8.2132 \\
$\begin{array}{l}\text { Villalva } \\
(2009) \text {-numerical- }\end{array}$ & 1.3 & 0.221 & 415.405 & $9.825 \cdot 10^{-8}$ & 8.214 \\
\hline
\end{tabular}


Table 8

I-V curve from a Photowatt-PWP 201 solar module composed of 36 solar cells connected in series [11].

\begin{tabular}{ll}
\hline \multicolumn{2}{l}{ Photowatt-PWP 201 solar module } \\
\hline$V[\mathrm{~V}]$ & $I[\mathrm{~A}]$ \\
\hline-1.9426 & 1.0345 \\
0.1248 & 1.0315 \\
1.8093 & 1.0300 \\
3.3511 & 1.0260 \\
4.7622 & 1.0220 \\
6.0538 & 1.0180 \\
7.2364 & 1.0155 \\
8.3189 & 1.0140 \\
9.3097 & 1.0100 \\
10.2163 & 1.0035 \\
11.0449 & 0.9880 \\
11.8018 & 0.9630 \\
12.4929 & 0.9255 \\
12.649 & 0.9120 \\
13.1231 & 0.8725 \\
14.2221 & 0.7265 \\
14.6995 & 0.6345 \\
15.1346 & 0.5345 \\
15.5311 & 0.4275 \\
15.8929 & 0.3185 \\
16.2229 & 0.2085 \\
16.5241 & 0.1010 \\
16.7987 & -0.0080 \\
17.0499 & -0.1110 \\
17.2793 & -0.2090 \\
17.4885 & -0.3030 \\
\hline & \\
\hline
\end{tabular}

the characteristic points of the $I-V$ curve, obtained from the calculated equivalent circuit have been included. As expected, they are quite exact, validating all the simplifications made within the development of the present method.

As said, an additional validation has been made to check this method, based on a solar panel benchmarking $I-V$ curve from Refs. [11], see Table 8 . This experimentally measured $I-V$ curve corresponds to a Photowatt-PWP 201 solar module (Photowatt, Bourgoin-jallieu, France), composed of 36 solar cells connected in series and measured at $45^{\circ} \mathrm{C}$. It has been widely used by different authors as benchmark to check electric circuit models and methods developed for parameter extraction [30-33,48-51]. The three characteristic points of the $I-V$ curve are included in Table 9, these points were extrapolated in Ref. [11] from the experimental data. In order to check the present method, the results from a 1-diode/2resistors equivalent circuit calculated from the data included in Table 9 are compared to the results from Table 8 . Also, the results are compared to the ones resulting from Phang et al. (1984) analytical method, based on the mentioned three characteristic points of the $I-V$ curve (estimating the slopes of the $I-V$ curve at the open circuit and short circuit points with these data). In this case, the starting point is the estimation of the slope $R_{\text {sho }}$, instead of the ideality factor, $a$. Following the empirical procedure described by Orioli and Di Gangi (2013), the slopes of the $I-V$ curve at the open circuit and short circuit points are [47]:

Table 9

Values of the current and voltage at short circuit, open circuit, and maximum power points $\left(I_{s c}, V_{o c}, V_{m p}, I_{m p}\right)$, calculated for a Photowatt-PWP 201 solar module (see Ref. [11]) from experimental data.

\begin{tabular}{lc}
\hline & Photowatt-PWP 201 solar module \\
\hline$V_{o c}\{\mathrm{~V}\}$ & 16.7785 \\
$I_{s c}\{\mathrm{~A}\}$ & 1.0317 \\
$V_{m p}\{\mathrm{~V}\}$ & 12.6490 \\
$I_{m p}\{\mathrm{~A}\}$ & 0.9120 \\
\hline
\end{tabular}

Table 10

Parameters of 1-diode/2-resistors circuit model adjusted with the presented methodology to the Photowatt-PWP 201 solar module behavior (Table 8). The results from other authors have also been included in the table.

\begin{tabular}{llllll}
\hline Model & $a$ & $R_{5}\{\Omega\}$ & $R_{5 h}\{\Omega\}$ & $I_{0}\{\mathrm{~A}\}$ & $I_{p v}\{\mathrm{~A}\}$ \\
\hline $\begin{array}{c}\text { Present } \\
\text { method -analytical- }\end{array}$ & 45.1958 & 1.3535 & 559.6804 & $1.3214 \cdot 10^{-6}$ & 1.0342 \\
$\begin{array}{c}\text { Phang et al. } \\
\quad(1984) \text {-analytical- } \\
\quad \text { [42] }\end{array}$ & 63.3689 & 0.0832 & 561.0340 & $6.4049 \cdot 10^{-5}$ & 1.0319 \\
$\begin{array}{c}\text { Easwarakhanthan } \\
\quad(1986) \text { [11] }\end{array}$ & 48.4500 & 1.2057 & 549.4500 & $3.2875 \cdot 10^{-6}$ & 1.0318 \\
$\begin{array}{c}\text { AlHajri et al. } \\
\text { (2012) [51] }\end{array}$ & 48.2889 & 1.2053 & 714.2857 & $3.1756 \cdot 10^{-6}$ & 1.0313 \\
$\begin{array}{c}\text { Bouzidi et al. } \\
\text { (2007) [48] }\end{array}$ & 48.1862 & 1.2030 & 555.5556 & $3.0760 \cdot 10^{-6}$ & 1.0339 \\
$\begin{array}{c}\text { AlRashidi et al. } \\
\text { (2011) [31] }\end{array}$ & 48.5862 & 1.1968 & 555.5556 & $3.4360 \cdot 10^{-6}$ & 1.0441 \\
$\begin{array}{c}\text { Wei et al. } \\
\text { (2011) [49] }\end{array}$ & 52.2430 & 1.0755 & 1850.1000 & $8.3010 \cdot 10^{-6}$ & 1.0286 \\
$\begin{array}{c}\text { El-Naggar et al. } \\
\text { (2012) [50] }\end{array}$ & 48.8211 & 1.1989 & 833.3333 & $3.6642 \cdot 10^{-6}$ & 1.0331 \\
$\begin{array}{c}\text { Peng et al. } \\
\text { (2013) [30] }\end{array}$ & 48.3221 & 1.2132 & 625.0000 & $3.2212 \cdot 10^{-6}$ & 1.0313 \\
\begin{tabular}{c} 
Gong (2013) \\
\hline (2013
\end{tabular} & 48.6428 & 1.2013 & 981.9822 & $3.4823 \cdot 10^{-6}$ & 1.0305 \\
\hline
\end{tabular}

$R_{S O}=C_{5} \frac{V_{o c}}{I_{S C}}$,

$R_{\text {sho }}=C_{s h} \frac{V_{o c}}{I_{S C}}$,

where $C_{s}=0.11175$ and $C_{s h}=34.49692$. Based on the above expressions $R_{s 0}=1.817$ and $R_{s h 0}=561.034$ for the analyzed solar array. The procedure followed for the present calculations can be summarized as follows:

- Estimate $R_{\text {sho }}$ with expression (31).

- Obtain $R_{S}$ from expression (25).

- Obtain $a$ from expression (24).

- Obtain $R_{s h}$ from expression (17).

- Obtain $I_{0}$ from expression (9).

- Obtain $I_{p v}$ from expression (7).

In Table 10 the calculated parameters of the 1-diode/2-resistors circuit model equivalent to the mentioned solar module are included. In this table the results obtained numerically by other authors have been also included, this information has been summarized by AlRashidi et al. [31]. In Fig. 3, the difference between the calculated and the benchmark experimental $I-V$ curve from Table $8, I-I_{\text {curve }}$, is shown for the mentioned solar module. Results from the other authors have also been included in the figure. It can be observed that with the proposed analytical method based on manufacturers' data, it is possible to derive the 1-diode/2-resistors circuit model parameters, obtaining similar results to other more complicated numerical methods.

To globally compare the results, some authors have used the non-dimensional standard deviation, SD, as defined by Easwarakhanthan [11]:

$S D=\sqrt{\frac{1}{m} \sum_{i=1}^{m}\left(\frac{I_{\text {calc }, i}}{I_{i}}-1\right)^{2}}$,

where $I_{\text {calc, } i}$ and $I_{i}$ are, respectively, the current calculated with the electric model and the measured current at a certain point, $i$, of the $I-V$ curve, and $m$ is the number of points on the curve. This 


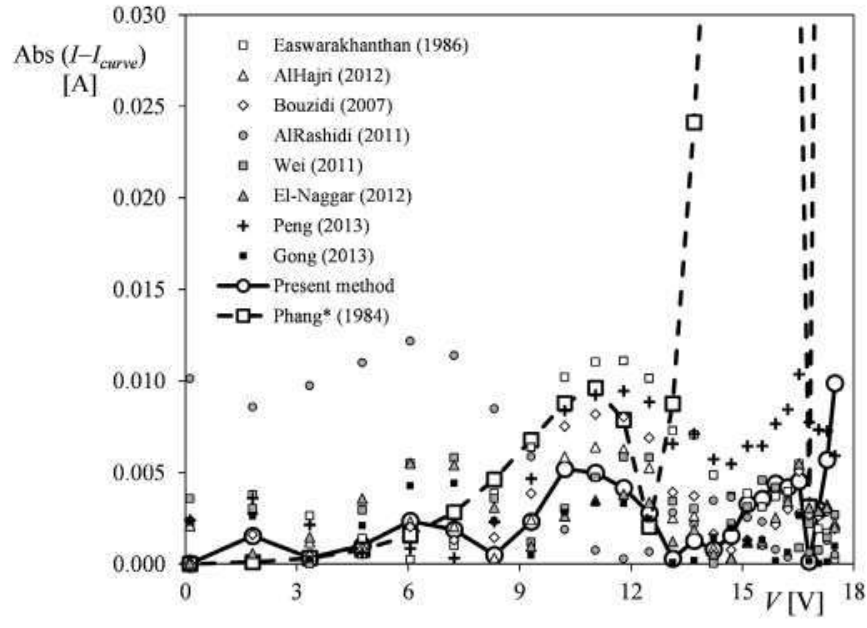

Fig. 3. Difference between the calculated and the experimental $I-V$ curves with regard to the Photowatt-PWP 201 solar module. $\left({ }^{*}\right)$ Some points with regard to the Phang method are out of scale.

\section{Table 11}

Non-dimensional standard deviation, $\xi$, calculated, using the proposed method, with respect to the experimental values of the $I-V$ curves of the R.T.C. France silicon cell, and the Photowatt-PWP 201 solar module. Results from other numerical methods from the available literature have also been included. See also Fig. 3.

\begin{tabular}{lll}
\hline Model & \multicolumn{2}{l}{ Photowatt-PWP 201 solar module } \\
\cline { 2 - 3 } & $\xi$ & $\xi\left({ }^{*}\right)$ \\
\hline Present method & $2.85 \cdot 10^{-3}$ & $2.86 \cdot 10^{-3}$ \\
Phang (1984) [42] & $3.44 \cdot 10^{-2}$ & $2.05 \cdot 10^{-2}$ \\
Easwarakhanthan (1986) [11] & $5.90 \cdot 10^{-3}$ & $8.42 \cdot 10^{-3}$ \\
AlHajri (2012) [51] & $3.23 \cdot 10^{-3}$ & $4.15 \cdot 10^{-3}$ \\
Bouzidi (2007) [48] & $3.89 \cdot 10^{-3}$ & $5.53 \cdot 10^{-3}$ \\
AlRashidi (2011) [31] & $6.02 \cdot 10^{-3}$ & $2.22 \cdot 10^{-3}$ \\
Wei (2011) [49] & $3.61 \cdot 10^{-3}$ & $4.04 \cdot 10^{-3}$ \\
El-Naggar (2012) [50] & $2.84 \cdot 10^{-3}$ & $2.44 \cdot 10^{-3}$ \\
Peng (2013) [30] & $6.16 \cdot 10^{-3}$ & $7.49 \cdot 10^{-3}$ \\
Gong (2013) & $2.20 \cdot 10^{-3}$ & $2.02 \cdot 10^{-3}$ \\
\hline
\end{tabular}

parameter can compare results from different $I-V$ curves. However, it excessively takes into account the errors around the open circuit point. As a solution, it seems better to define a non-dimensional standard deviation, $\xi$, based on the RMSE parameter proposed by Askarzadeh [32,33], divided by the short circuit current, $I_{s c}$, in order to make it non-dimensional:

$\xi=\frac{\text { RMSE }}{I_{s c}}=\frac{1}{I_{s c}} \sqrt{\frac{1}{m} \sum_{i=1}^{m}\left(I_{\mathrm{cal}, i}-I_{i}\right)^{2}}$.

In Table 11 the values of the comparison parameter, $\xi$, are included for the solar module. Two different calculations have been done, in the first the voltage range $\left[0, V_{o c}\right]$ is taken into account, whereas in the second only a $\pm 10 \%$ bracket of the open circuit voltage, $V_{o c}$, around the maximum power point is taken into account. The results suggest that, for the studied solar panel, with a good knowledge of the characteristic points of the $I-V$ curve and applying the present analytical method, it is possible to define an equivalent circuit that reproduces the experimental $I-V$ curve with similar accuracy to the ones calculated with numerical methods.

\section{Conclusions}

In the present study, a new analytical method to extract the parameters of a 1-diode/2-resistors electric circuit equivalent to a photovoltaic array is developed and analyzed. The major conclusions resulting from this work are:

- The method is based on the manufacturer's datasheet of the photovoltaic system (short circuit, maximum power and open circuit points).

- Terms in the equations neglected in the analytical models of previous authors are considered relevant enough to be introduced in the final expressions without increasing their complexity.

- The first derivative of the power with respect to the output voltage equal to zero is considered as a boundary condition in the method developed in the present study. As far as the authors know, this boundary condition is not considered in other analytical methods.

- The above two conditions ensure better results around the maximum power point.

- Results indicate that the calculated equivalent electric circuit reproduces the $I-V$ curve with similar, and even better, accuracy to numerical methods with higher computational requirements.

\section{Acknowledgments}

The present work was carried out in the framework of the UPMSat-2 satellite project at the IDR/UPM Institute (Madrid, Spain). The authors are indebted to the IDR/UPM Institute and the IES/UPM Institute for the support given to the present research. The authors would also like to thank José María Ruíz, from the IES/UPM Institute for his useful comments on the text. The authors are truly grateful to Anna María Ballester for her kind help in improving the style of the text, and her encouraging support. Finally, the authors would like to thank the reviewers for their help in improving the present work.

\section{References}

[1] W. Pfann, W. Van Roosbroeck, J. Appl. Phys. 25 (1954) 1422.

[2] M.B. Prince, J. Appl. Phys. 26 (1955) 534.

[3] P.A. Iles, IRE Trans. Mil. Electron. MIL-6 (1962) 5.

[4] M. Wolf, H. Rauschenbach, Adv. Energy Convers. 3 (1963) 455.

[5] S.M. Sze, Physics of Semiconductor Devices, John Wiley and Sons, New York, 1969.

[6] H. Rauschenbach, Solar Cell Array Design Handbook, vol. 1, let Propulsion Laboratory, California Institute of Technology, Pasadena, California 91103. 1976.

[7] E.E. van Dyk, E.L. Meyer, Renewable Energy 29 (2004) 333.

[8] M.G. Villalva, J.R. Gazoli, E.R. Filho, IEEE Trans. Power Electron. 24(2009) 1198.

[9] M.G. Villalva, J.R. Gazoli, E.R. Filho, Brazilian Power Electronics Conference, 2009, p. 1244.

[10] Q. Jia, K. Ebihara, T. Ikegami, Philos. Mag. B 72 (1995) 375.

[11] T. Easwarakhanthan, J. Bottin, 1. Bouhouch, C. Boutrit, Int. J. Sol. Energy 4 (1986) 1.

[12] C. Garrido-Alzar, Renewable Energy 10 (1997) 125.

[13] F. Petcut, T. Leonida-Dragomir, J. Control Eng. Appl. Inform. 12 (2010) 30.

[14] J.A. Gow, C.D. Manning, IEE Proc. - Electric Power Appl. 146 (1999) 193.

[15] J.A. Eikelboom, A.H.M.E. Reinders, in: Proceedings of the 4th European PV Solar Energy Conference, 1997, pp. 293-296.

[16] M.A. de Blas, J.L Torres, E. Prieto, A. García, Renewable Energy 25 (2002) 371.

[17] C. Carrero, J. Rodriguez, D. Ramírez, C. Platero, Renewable Energy 35 (2010) 1103.

[18] X.-G. Zhu, Z.-H. Fu, X.-M. Long, Sol. Energy 85 (2011) 393.

[19] D.L. Bätzner, A. Romeo, H. Zogg, A.N. Tiwari, in: 17-th EC PV Solar Energy Conference, Munich, Germany, 2001, pp. 1-4.

[20] K.L Kennerud, IEEE Trans, Aerosp. Electron. Syst. 5 (1969) 912.

[21] J. Charles, M. Abdelkrim, Y. Muoy, P. Mialhe, Sol. Cells 4 (1981) 169.

[22] W. De Soto, S.A. Klein, W.A. Beckman, Sol. Energy 80 (2006) 78.

[23] C. Carrero, J. Amador, S. Arnaltes, Renewable Energy 32 (2007) 2579.

[24] R. Chenni, M. Makhlouf, T. Kerbache, A. Bouzid, Energy 32 (2007) 1724

[25] E. Saloux, A. Teyssedou, M. Sorin, Sol. Energy 85 (2011) 713.

[26] B. Galiana, C. Algora, I. Reystolle, Sol. Energy Mater. Sol. Cells 90 (2006) 2589.

[27] C. Domínguez, l. Antón, G. Sala, Prog. Photovoltaics: Res. Appl. 18 (2010) 272.

[28] Y. Li, W. Huang, H. Huang, C. Hewitt, Y. Chen, G. Fang, D.L Carroll, Sol. Energy 90 (2013) 51.

[29] A.K. Das, Sol. Energy 85 (2011) 1906. 
[30] L. Peng, Y. Sun, Z. Meng, Y. Wang, Y. Xu, J. Power Sources 227 (2013) 131.

[31] M.R. AlRashidi, M.F. AlHajri, K.M. El-Naggar, A.K. Al-Othman, Sol. Energy 85 (2011) 1543.

[32] A. Askarzadeh, A. Rezazadeh, Sol. Energy 86 (2012) 3241.

[33] A. Askarzadeh, A. Rezazadeh, Appl. Energy 102 (2013) 943.

[34] A. ALOahtani, Energytech, IEEE, Cleveland, Ohio, 2012, pp. 1-6 n.d.

[35] M. Averbukh, S. Lineykin, A. Kuperman, Prog. Photovoltaics Res. Appl. 21 (2012) 1016

[36] A. Chatteriee, A. Keyhani, D. Kapoor, IEEE Trans. Fnergy Convers. 26 (2011) 883.

[37] A.K. Das, Renewable Energy 52 (2013) 95.

[38] S. Lineykin, Electric. Eng. Electron. (2012) 1.

[39] Y. Kuo, T. Liang, J. Chen, IEEE Trans, Ind. Electron. 48 (2001) 594.

[40] G. Walker, J. Electr. Electron. Eng 21 (2001) 49.

[41] D.S.H. Chan, J.C.H. Phang, IEEE Trans, Electron Dev. 34 (1987) 286.

[42] J.C.H. Phang, D.S.H. Chan, J.R. Phillips, Electron. Lett. 20 (1984) 406.

[43] V. Lo Brano, A. Orioli, G. Ciulla, A. Di Gangi, Sol. Energy Mater. Sol. Cells 94 (2010) 1358
[44] M. Di Piazza, G. Vitale, Photovoltaic Sources: Modelling and Emulation, Springer, London, 2013.

[45] D. Sera, R. Teodorescu, P. Rodriguez, in: IEEE International Symposium on Industrial Electronics (ISIE), 2007, pp. 2392-2396.

[46] W. Xiao, W.G. Dunford, A. Capel, IEEE 35th Annual Power Electronics Specialists Conference (IEEE Cat. No. 04CH37551), 2004, p. 1950.

[47] A. Orioli, A. Di Gangi, Appl. Energy 102 (2013) 1160.

[48] K. Bouzidi, M. Chegaar, A. Bouhemadou, Sol. Energy Mater. Sol. Cells 91 (2007) 1647

[49] H. Wei, J. Cong, X. Lingyun, S. Deyun, in: 2011 International Conference on Electric Information and Control Engineering (ICEICE), 2011, pp. 398402.

[50] K.M. El-Naggar, M.R. AlRashidi, M.F. AlHajri, A.K. Al-Othman, Sol. Energy 86 (2012) 266

[51] M.F. AlHajri, K.M. El-Naggar, M.R. AlRashidi, A.K. Al-Othman, Renewable Energy 44 (2012) 238 